Aspectos contables y tributarios de la Norma Internacional de Contabilidad № 23 Costos por Préstamos, en empresas comerciales de Paraguay. Periodo 2018

\title{
Accounting and tax aspects of the International Accounting Standard No. 23 Costs for Loans, in commercial companies of Paraguay. Period 2018
}

\section{Miguel Ángel Alegre Brítez1}

1Universidad Nacional de Asunción, Facultad de Ciencias Económicas. San Lorenzo, Paraguay Recibido: 30/11/2018 Aceptado: 18/01/2019

\section{RESUMEN}

Este trabajo analiza la vinculación entre el Decreto 6359/2005, Decreto 1030/2013 y la NIC 23 en cuanto a los intereses de financiación en empresas comerciales. La metodología consistió en: el enfoque fue cuantitativo, el alcance fue descriptivo y explicativo, el diseño fue no experimental de corte trasversal, el tipo de investigación fue bibliográfica y documental con ejercicios de simulación de asientos contables, el procesamiento de los ejercicios se hizo con Microsoft Excel (2016). Los principales resultados fueron: Los intereses a vencer afectan el patrimonio neto, los intereses pagados al estado de resultados y también al patrimonio neto, el IVA de los intereses está en estrecha relación con el IRACIS y ambos repercuten significativamente en el patrimonio de la empresa. Las principales conclusiones fueron: Los intereses por Préstamos contabilizados según la NIC 23 tienen directa vinculación con el IRACIS afectado por el Decreto 6539/2005 y el IVA por el Decreto 1030/2013 en la deducibilidad de dichos impuestos.

Palabras clave: Empresas, Comercio, Intereses, NIC 23

\section{ABSTRACT}

This paper analyzes the link between Decree 6359/2005, Decree 1030/2013 and IAS 23 regarding financing interests in commercial companies. The methodology consisted of: the approach was quantitative, the scope was descriptive and explanatory, the design was non-experimental crosssectional, the type of research was bibliographic and documentary exercises with simulation of accounting entries, the processing of the exercises was made Microsoft Excel (2016). The main results were: Interest due affects net worth, interest paid to the income statement and also net worth, interest VAT is closely related to the IRACIS and both have a significant impact on the company's equity. The main conclusions were: Interest on Loans accounted for under IAS 23 is directly linked to the IRACIS affected by Decree $6539 / 2005$ and VAT by Decree $1030 / 2013$ on the deductibility of said taxes.

Key words: Companies, Trade, Interests, IAS 23 
Autor correspondiente: Miguel Ángel Alegre Brítez. Doctor en Contabilidad. Universidad Nacional de Asunción, Facultad de Ciencias Económicas. San Lorenzo, Paraguay. Email: malegre333@gmail.com

\section{INTRODUCCIÓN}

El presente artículo científico está realizado a efectos de comparar a la Norma Internacional de Contabilidad № 23 Costos por Préstamos (NIC 23) emitida por la Consejo de Normas Internacionales de Contabilidad (IASB, por sus siglas en inglés), con los Decretos 1030/2013 "“Por el cual se reglamenta el Impuesto al Valor Agregado (IVA) establecido en la Ley $\mathrm{N}^{\circ}$ 125/1991 y sus Modificaciones", y 6359/2005 "Por el cual se reglamenta el Impuesto a la Renta de Actividades Comerciales, Industriales o de Servicios previsto en el Capítulo I del Libro I de la Ley $N^{\circ} 125 / 1991$, adecuándolo a las Modificaciones introducidas en la Ley N²421/2004" . El problema surge, debido a existen algunos criterios tributarios que no permiten la deducibilidad de los intereses pagados en concepto de préstamos, en algunas situaciones, además la erogación por estos pagos afecta y está vinculada con el Impuesto al Valor Agregado (IVA), lo cual tiene un efecto colateral y de sobremanera al patrimonio de la entidad. Se denomina intereses a la porción de dinero que paga un prestatario por el capital recibido de un prestamista, luego de un periodo dado, bajo una tasa de interés y otras condiciones de financiación establecidas entre ambas partes. Este trabajo trata sobre diversos aspectos contables y tributarios de los intereses y su influencia en las empresas comerciales.

Según Rodríguez (2013) la empresa es una organización que coordina la disposición de los recursos y factores, a los efectos de la generación de un servicio o empleo para la obtención de un beneficio desde de transacciones realizadas en el mercado, con un riesgo inherente a esa actividad comercial. Además, como complemento a lo dicho, Sabino (1991) menciona que el comercio es el intercambio de bienes y servicios directo, bajo la forma de trueque, o por medio del dinero. La tendencia al cambio de bienes diferentes responde a un criterio de maximización de utilidad que se desarrolla en los seres humanos desde sus más tempranos orígenes. El comercio, puede decirse, es la expresión más o menos consolidada y estable de esta tendencia natural al intercambio. Por lo tanto, Horngren et al. (2012) define a las empresas comerciales como aquellas que compran y venden posteriormente bienes tangibles sin que los alteren en su forma básica, este sector de negocios incluye a las que se dedican a ventas del menudeo, así como también ventas al por mayor.

EI Principio Básico de la NIC 23, se establece así “Los costos por préstamos que sean directamente atribuibles a la adquisición, construcción o producción de un activo apto forman parte del costo de dichos activos. Los demás costos por préstamos se reconocen como gastos. Son costos por préstamos los intereses y otros costos en los que la entidad incurre, que están relacionados con los fondos que ha tomado prestados" (Fundación IFRS, 2014, pág. 1). La activación se considera como gasto temporal realizado, es significativo y su realización determina que dicho activo esté en funcionamiento y condiciona a la realización de ingresos, en cambio se nota que para las Normas Internacionales de Información Financiera para las Pequeñas y Medianas Empresas (NIIF para PYMES), los costos por préstamos se consideran directamente un gasto, por una cuestión de facilidad en su medición o registración, ya que este tipo de empresas no posee tanta complejidad en sus sistemas de información financiera y contable.

Ortiz y Rivero (2006) mencionan sobre los costos indirectos "son costos en común que no son fácilmente identificables con objetivos finales. Los costos indirectos benefician - aunque indirectamente- a los financiadores que trabajan con la organización. Son ejemplos de costos indirectos: el costo de la gerencia, las funciones de investigación y desarrollo, costos de oficina, 
TIC, costos financieros, costos administrativos, de personal y capacitación", esto conlleva a que los intereses establecidos en los préstamos puedan ser tomados como costos indirectos, pues los mismos tienen afectación a distintos activos de las empresas.

El reconocimiento de los costos por préstamos se da en la siguiente manera: "Una entidad capitalizará los costos por préstamos que sean directamente atribuibles a la adquisición, construcción o producción de activos aptos, como parte del costo de dichos activos. Una entidad deberá reconocer otros costos por préstamos como un gasto en el periodo en que se haya incurrido en ellos. Un activo apto, es aquel el que requiere, necesariamente, de un periodo sustancial antes de estar listo para el uso al que está destinado o para la venta" (Fundación IFRS, 2014, pág. 1). La capitalización y su metodología estará circunscripta principalmente al porcentaje de avance de las obras del activo, esto se debe a que es un criterio mayormente eficiente para el prorrateo de dichos costos financieros, un ejemplo de activo apto es una máquina de gran porte que tiene varias partes individuales que serán ensambladas con la parte principal a efectos de su funcionamiento.

"Una entidad suspenderá la capitalización de los costos por préstamos durante los periodos en los que se haya suspendido el desarrollo de actividades de un activo apto, si estos periodos se extienden en el tiempo. Una entidad cesará la capitalización de los costos por préstamos cuando se hayan completado todas o prácticamente todas las actividades necesarias para preparar al activo apto para el uso al que va destinado o para su venta" (Fundación IFRS, 2014, pág. 2). La suspensión de la capitalización estará supeditada al tiempo en que dicho activo apto esté en proceso de construcción, así como cuando se haya suspendido su construcción por fuerza mayor, o en el momento en que se haya terminado completamente. La diferencia de intereses correspondientes a los periodos no capitalizados será registrada como gasto, principalmente en intereses pagados o intereses devengados del periodo.

En cuanto al tratamiento tributario de los intereses en Paraguay, se comentan dos Decretos importantes que tienen relación con la NIC 23, los cuales son Decreto 6359/2005 "Por el cual se reglamenta el Impuesto a la Renta de Actividades Comerciales, Industriales o de Servicios previsto en el Capítulo I del Libro I de la Ley N 125/1991, adecuándolo a las Modificaciones introducidas en la Ley $N^{\circ} 2421 / 2004$ " y el Decreto 1030/2013 "Por el cual se reglamenta el Impuesto al Valor Agregado (IVA) establecido en la Ley $N^{\circ} 125 / 1991$ y sus Modificaciones". Estos dos decretos son de relevancia, pues afectan a resultados del periodo y, además, tienen un efecto financiero y patrimonial que reducirían la capacidad de pago de la empresa, si no estuvieren bien calculados y considerados desde el punto de vista impositivo.

Los descuentos por intereses de deudas vencidas que tuvieren quitas según la Ley 154/1969 de Quiebras serán reversados en el periodo fiscal que correspondan y no constituyen hechos gravados por el IVA e IRACIS puesto que son realizados bajo concordato con sentencia del juez de quiebras (). Sin embargo, las rebajas de intereses por transacciones comerciales en condiciones normales de financiación, constituirán actividades gravadas para el IRACIS (Poder Ejecutivo, 2005). Estas rebajas afectarían al patrimonio neto, pues la disminución de pasivo será registrada contra una cuenta de resultados positivo en el periodo que corresponda. En tanto, dure el proceso de análisis de la rebaja por parte del proveedor, no se registrará un ingreso, ya que se perdería el principio de prudencia en las registraciones contables, el cual dice que los ingresos serán registrados cuando se realizan, y los gastos cuando se los conocen, sin que importe el periodo anterior al de su posible devengamiento.

También se menciona en el artículo № 47 del Decreto 6359/2005 en cuanto a los intereses "Serán deducibles los intereses pagados por las entidades bancarias o financieras al dueño o accionista de la entidad, en concepto de depósitos en cuenta o cualquier otra inversión de los mismos, siempre que sean a tasas pasivas a nivel bancario y financiero. Las tasas pasivas a nivel bancario 
y financiero a que se refiere la última parte del inc. a) del Art. 9o de la Ley, serán las publicadas por el Banco Central del Paraguay con referencia al promedio ponderado nominal vigente en el periodo de pago" (Poder Ejecutivo, 2005). Estos intereses son deducibles pues corresponden a la operativa normal de las entidades sujetas a la ley 861/1996 tales como Bancos y Financieras (Congreso de la Nación Paraguaya, 1996).

Los Gastos Deducibles son mencionados en el artículo № 49 del Decreto 6359/2005 así “No se podrán deducir los siguientes gastos: Intereses por concepto de capitales, préstamos o cualquier otra inversión del dueño, socio o accionista de la empresa, salvo que dichos montos estén alcanzados por el Impuesto y no excedan el promedio de las tasas máximas pasivas del mercado bancario y financiero de acuerdo con los términos establecidos en el inciso a) del Art. $9^{\circ}$ de la Ley 125/1991" (Poder Ejecutivo, 2005). Este artículo está en directa relación con la deducibilidad contemplada cuando la transacción esté vinculada directamente con el giro del negocio. Además, no se debe pasar el límite de deducibilidad de las tasas según la Ley 861/1996. El artículo № 55 del Decreto 6359/2005 menciona en cuanto a los Bienes del Activo Fijo "El valor de costo de los bienes muebles del activo fijo está constituido por el precio de adquisición más los gastos efectuados con motivo de su compra e instalación, excluyéndose los intereses de financiación y las diferencias de cambio" (Poder Ejecutivo, 2005).

Los bienes del activo fijo se registran por su valor factura más todos otros costos relacionados a su puesta en marcha. La fórmula para su costo es $C A=P C+A I+O I+O C D$

En donde

$\mathrm{CA}=$ Costos de Adquisición

$\mathrm{PC}=$ Precio de Compra sin IVA

$\mathrm{Al}=$ Aranceles de Importación sin IVA

$\mathrm{OI}=$ Otros impuestos no recuperables en su naturaleza

COD $=$ Otros costos directos

Los activos fijos son partidas no monetarias, por tanto, no tienen variación por el tipo de cambio en su adquisición. En cambio, el pasivo generado por dicha compra si sería afectado. Los intereses de financiación de activos están contemplados en la NIC 23, en el periodo que dure su uso. Pero a efectos tributarios, se hacen los ajustes necesarios en los Estados Financieros a fin de ejercicio, para que reflejen la porción de deducibilidad o no deducibilidad de la transacción. Otro Decreto importante que trata sobre los Intereses es el Decreto 1030/2013 "Por el cual se reglamenta el Impuesto al Valor Agregado (IVA) establecido en la Ley $\mathrm{N}^{\circ} 125 / 1991$ y sus Modificaciones". El artículo № 11 de dicho Decreto menciona el Nacimiento de la Obligación Tributaria, de la siguiente manera "Sin perjuicio de lo dispuesto en el artículo № 80 de la Ley 125/1991, se entenderá que el hecho imponible se ha configurado: f) En el caso de arrendamiento financiero, en el momento del vencimiento de cada cuota. Si se ejerciere la opción de compra, en el momento del pago total o parcial del saldo del precio, g) En el caso de intereses resarcitorios y/o punitorios como consecuencia del incumplimiento del pago de la operación, en el momento de su percepción. A este efecto, estos intereses se considerarán percibidos cuando se produzca una real transferencia de recursos a favor del perceptor, mediante un pago en efectivo o en especie, o mediante débito en la cuenta del prestatario" (Poder Ejecutivo, 2013).

Un arrendatario contabiliza un arrendamiento financiero como una compra de un activo a crédito (pues al inicio del arrendamiento, el arrendatario reconoce los derechos y las obligaciones que surgen del arrendamiento por importes equivalentes al valor razonable del activo arrendado, o bien al valor presente de los pagos mínimos por el arrendamiento, si éste fuera menor). Por el contrario, un arrendador contabiliza un arrendamiento financiero mediante el reconocimiento de una cuenta por cobrar (activo). El arrendador, que a la vez sea fabricante o distribuidor, contabiliza un arrendamiento financiero como la venta de un activo a crédito. El arrendatario 
reparte los pagos mínimos por el arrendamiento entre la carga financiera (gastos por intereses) y el reembolso del pasivo del arrendamiento financiero empleando el método del interés efectivo. Además, Allen et. al (2010) enfatizan que el arrendatario(usuario) promete hacer una serie de pagos al arrendador (dueño), el contrato de arrendamiento especifica la modalidad de pago, cuando se termina el arrendamiento, el equipo se devuelve al arrendador, sin embargo, es frecuente que el contrato de arrendamiento conceda al usuario la opción de comprar el equipo o rentar de nuevo.

Por lo tanto, según (Saavedra, 2010) El contrato de arrendamiento financiero deberá estipular el monto del capital financiado, así como el valor de la opción de compra y de las cuotas pactadas, discriminando capital e intereses. Los Préstamos y Financiaciones por la Enajenación de Bienes y la Prestación de Servicios se desarrollan en el artículo № 12 del Decreto 1030/2013 en esta forma: "Los intereses, comisiones y recargos provenientes de los préstamos y financiaciones otorgados por el propio enajenante del bien o prestador de servicio, o por entidades no reguladas o no por la ley 861/1996, estarán sujetas a la tasa del diez por ciento (10\%)" (Poder Ejecutivo, 2014). La tasa del IVA al $10 \%$ está generalizada para todos los intereses de bancos, financieras, casas de préstamos entre otros. Esto se dio debido a la distorsión que existía anteriormente en cuanto a los sectores involucrados en la financiación de las actividades empresariales. Con esta tasa se controlaría mejor los ingresos y egresos financieros de dichas entidades.

Luego de lo expuesto anteriormente, la pregunta general que surge en este trabajo es ¿Cuáles son los aspectos contables y tributarios de la Norma Internacional de Contabilidad № 23 Costos por préstamos en empresas comerciales de Paraguay en el periodo 2018? Como objetivo general de este trabajo se tiene "Analizar los Aspectos contables y tributarios de la Norma Internacional de Contabilidad № 23 Costos por Préstamos, en empresas comerciales de Paraguay en el periodo 2018". Además, surge la hipótesis de investigación "La registración contable en base la NIC 23, Decreto № 6359/2005 y Decreto № 1030/2013 influyen significativamente en el patrimonio de empresas comerciales".

\section{MATERIALES Y MÉTODOS}

El trabajo tuvo un enfoque cuantitativo, pues se midieron las variables establecidas en los dos ejercicios propuestos mediante simulación de cuentas que afectaron los intereses y se vio la vinculación tributaria en los Decretos 6359/2005 y Decreto 1030/2013 establecidos por el Poder Ejecutivo en Paraguay con la NIC 23 Costos por Préstamos, establecida por la IASB. Se hace énfasis que, en Paraguay, todos los Decretos son establecidos por dicho Poder Ejecutivo y las Leyes por el Congreso de la Nación Paraguaya. El diseño de la investigación fue el experimental, pues se crearon modelos de ejercicios contables a efectos de verificar la manipulación de las variables "cuentas" relacionadas a los intereses y su influencia en las otras cuentas contables a través de los impuestos aplicados a las mismas en asientos contables, estas cuentas que principalmente afectan al patrimonio son las de intereses registradas en los rubros de activo y de egresos. El corte de la investigación fue trasversal, pues el trabajo se realizó en el año 2018 y no se hicieron seguimientos de las variables de estudio (intereses).

El tipo de investigación fue además bibliográfica y documental, pues se analizaron las reglamentaciones tributarias (leyes y decretos reglamentarios) y las normativas contables que afectaron al tratamiento de los intereses, tales como las Normas Internacionales de Información Financiera. El método de análisis fue el inductivo que consistió en la verificación de las vinculaciones de los intereses en lo relacionado a las cuentas del activo, pasivo y por sobre todo las que afectan al estado de resultados, lo cual fue generalizado mediante los dos ejercicios propuestos. La manipulación de los datos y resultados de los ejercicios se realizó en 
el programa Microsoft Excel (2016) con la elaboración de los asientos contables y los estados financieros (balance general y estado de resultados). El alcance de la investigación fue descriptivo y explicativo, ya que se analizó la causa en la manipulación de las cuentas de intereses y su efecto en el patrimonio de la empresa, mediante el cálculo de los intereses que afectaron a las transacciones propuestas como simulación de ejercicio.

\section{RESULTADOS Y DISCUSIÓN}

A modo de ejemplificar la vinculación de la NIC 23 Costos por Préstamos con el IVA y el IRACIS, a continuación, se proponen dos ejercicios en forma de simulación de transacciones realizadas por empresas comerciales, en los cuales se contabilizan los intereses de los préstamos en cuentas de activo y de egresos. El propósito de estos ejercicios es ver los movimientos que dichas cuentas generan en el patrimonio neto y su repercusión financiera.

\section{Intereses por Adquisición de Activos}

El 05 de enero de 2018 la empresa DK S.A. ha realizado la compra de una maquinaria con la finalidad de utilizarla en sus actividades. La adquisición ha sido realizada mediante un préstamo en una casa de crédito por Gs. 100.000 .000 con un interés de Gs. 35.000 .000 a ser pagadero el 30 de junio del mismo año.

El detalle de los asientos contable se presenta a continuación (tabla 1).

Tabla 1. Libro Diario

\begin{tabular}{|c|c|c|c|c|}
\hline Fecha & Rubro & Concepto & Débitos & Créditos \\
\hline 02/01/2018 & Activo & Bancos Cta. Cte. & 170.000 .000 & \\
\hline 02/01/2018 & Patrimonio Neto & Capital & & 170.000 .000 \\
\hline $02 / 01 / 2018$ & $\mathrm{E}$ & Saldo Inicial & & \\
\hline 05/01/2018 & Activo & Bancos Cta. Cte. & 100.000 .000 & \\
\hline 05/01/2018 & Pasivo & Préstamos No Financieros & & 100.000 .000 \\
\hline 05/01/2018 & E & $\begin{array}{l}\text { Por la recepción del préstamo según } \\
\text { comprobantes }\end{array}$ & & \\
\hline $05 / 01 / 2018$ & Activo & Maquinarias y Equipos & 100.000 .000 & \\
\hline 05/01/2018 & Activo & IVA Crédito Fiscal & 10.000 .000 & \\
\hline 05/01/2018 & Activo & Bancos Cta. Cte. & & 110.000 .000 \\
\hline 05/01/2018 & E & $\begin{array}{l}\begin{array}{l}\text { Por compra de maquinarias, según } \\
\text { factura } \mathrm{N}^{\circ}\end{array} \\
\end{array}$ & & \\
\hline 05/01/2018 & Activo & Intereses a Vencer No Financieros & 35.000 .000 & \\
\hline 05/01/2018 & Pasivo & Intereses a Pagar No Financieros & & 35.000 .000 \\
\hline 05/01/2018 & $E$ & Provisión total de los intereses & & \\
\hline $30 / 06 / 2018$ & Egresos & Intereses Pagados No Financieros & 35.000 .000 & \\
\hline $30 / 06 / 2018$ & Activo & Intereses a Vencer No Financieros & & 35.000 .000 \\
\hline $30 / 06 / 2018$ & $\mathrm{E}$ & $\begin{array}{l}\text { Devengamiento de intereses, periodo } \\
\text { enero/iunio } 2018\end{array}$ & & \\
\hline $30 / 06 / 2018$ & Pasivo & Intereses a Pagar No Financieros & 35.000 .000 & \\
\hline $30 / 06 / 2018$ & Activo & IVA Crédito Fiscal & 3.500 .000 & \\
\hline $30 / 06 / 2018$ & Activo & Bancos Cta. Cte. & & 38.500 .000 \\
\hline $30 / 06 / 2018$ & $\mathrm{E}$ & $\begin{array}{l}\text { Pago de los intereses del periodo } \\
\text { enero/iunio } 2018\end{array}$ & & \\
\hline $30 / 06 / 2018$ & Pasivo & Préstamos No Financieros & 100.000 .000 & \\
\hline $30 / 06 / 2018$ & Activo & Bancos Cta. Cte. & & 100.000 .000 \\
\hline $30 / 06 / 2018$ & $\mathrm{E}$ & $\begin{array}{l}\text { Por el pago del préstamo contraído en } \\
\text { fecha } 05 / 01 / 2018\end{array}$ & & \\
\hline
\end{tabular}

Fuente: Elaboración Propia (2019). 
Tabla 2. Movimientos en el Balance General

\begin{tabular}{|lrrr|}
\hline \multicolumn{1}{|c}{ Rubro/Cuentas } & Débitos & Créditos & Saldo \\
Activo & $\mathbf{4 1 8 . 5 0 0 . 0 0 0}$ & $\mathbf{2 8 3 . 5 0 0 . 0 0 0}$ & $\mathbf{1 3 5 . 0 0 0 . 0 0 0}$ \\
Bancos Cta. Cte. & 270.000 .000 & 248.500 .000 & 21.500 .000 \\
Intereses a Vencer No Financieros & 35.000 .000 & 35.000 .000 & 0 \\
IVA Crédito Fiscal & 13.500 .000 & & 13.500 .000 \\
Maquinarias v Equipos & 100.000 .000 & & 100.000 .000 \\
Pasivo & $\mathbf{1 3 5 . 0 0 0 . 0 0 0}$ & $\mathbf{1 3 5 . 0 0 0 . 0 0 0}$ & $\mathbf{0}$ \\
Intereses a Paqar No Financieros & 35.000 .000 & 35.000 .000 & 0 \\
Préstamos No Financieros & 100.000 .000 & 100.000 .000 & 0 \\
Patrimonio Neto & & $\mathbf{1 7 0 . 0 0 0 . 0 0 0}$ & $\mathbf{- 1 7 0 . 0 0 0 . 0 0 0}$ \\
Capital & & 170.000 .000 & $-\mathbf{1 7 0 . 0 0 0 . 0 0 0}$ \\
$\quad$ Total qeneral & $\mathbf{5 5 3 . 5 0 0 . 0 0 0}$ & $\mathbf{5 8 8 . 5 0 0 . 0 0 0}$ & $\mathbf{- 3 5 . 0 0 0 . 0 0 0}$ \\
\hline
\end{tabular}

Fuente: Elaboración Propia (2019).

Tabla 3. Movimientos en el Estado de Resultados

\begin{tabular}{|c|c|c|c|}
\hline Rubro/Cuentas & Débitos & Créditos & Saldo \\
\hline Eqresos & 35.000 .000 & & -35.000 .000 \\
\hline Intereses Paqados No Financieros & 35.000 .000 & & -35.000 .000 \\
\hline Total qeneral & 35.000 .000 & & -35.000 .000 \\
\hline
\end{tabular}

Fuente: Elaboración Propia (2019).

En el ejercicio precedente se observa que la cuenta relacionada con el IVA es IVA Crédito Fiscal, la cual acumula los créditos en concepto de adquisiciones de mercaderías y pago de intereses (tabla 2). En cuanto al IVA sobre intereses es del 10\%. También se puede mencionar que la cuenta Intereses Pagados es deducible para el cálculo del IRACIS, toda vez que esté bien documentada. La cuenta intereses a vencer se cancela por ser una cuenta transitoria, cuya finalidad es reflejar los devengamientos pendientes de realizarse en el periodo. Es de mencionar que la adquisición de préstamos y pago de los mismos es una actividad de financiación para el Estado de Flujos de Efectivo, sin embargo, la adquisición de Maquinarias y Equipos es una Actividad de Inversión. La expresión "Entidades No Financieras" para este ejercicio, se refiere a las entidades no reguladas por la ley 861/1996 “De Bancos Financieras y Otras Entidades de Crédito” ni por la Ley 438/1994 "De Cooperativas" (tabla 3).

\section{Intereses con Partes Vinculadas}

La empresa LM S.R.L. ha obtenido un préstamo el 06/06/2018, de una entidad vinculada a ella la empresa PR S.A., por el importe de Gs. 250.000.000, con finalización el 30/11/2018 con la tasa del $10 \%$ anual. Los pagos y devengamientos se realizan el 30 de cada mes. La entidad realiza el devengamiento de los intereses mensualmente. Los ajustes por redondeo se realizan en la última cuota. En la tabla 4 se observa el siguiente esquema de pagos. 
Tabla 4. Datos del Crédito

\begin{tabular}{|l|r|}
\hline \multicolumn{1}{|c|}{ Concepto } & \multicolumn{1}{c|}{ Importe Gs. } \\
\hline Capital & 250.000 .000 \\
\hline Intereses (10\%) & 25.000 .000 \\
\hline Monto Total & 275.000 .000 \\
\hline Cuota Mensual & 45.833 .333 \\
\hline Amortización Mensual & 41.666 .667 \\
\hline Interés Mensual & 4.166 .663 \\
\hline
\end{tabular}

Fuente: Elaboración Propia (2019).

En el ejercicio precedente se observa que el IVA es deducible en su totalidad para el tomador del préstamo, y para el prestamista es un pasivo con el fisco (tabla 5). En cuanto al IRACIS, son deducibles los intereses pagados por estar devengados correctamente en el periodo del cual corresponde la financiación del préstamo. Esta operativa si es que la empresa la realiza habitualmente, en el flujo de efectivos se la clasifica como Actividades de Operación, en cambio, si los préstamos son realizados muy esporádicamente son clasificados como Actividades de Financiación (tabla 6). Las partes relacionadas, aunque sean los mismos directivos, a efectos contables son consideradas como fuentes de financiación externa. Los intereses a vencer en el flujo de efectivo no son considerados como actividades, pues no generan movimientos de efectivo (tabla 7).

Los principales resultados son que en ambos ejercicios se observa como la contabilización de los intereses afecta al patrimonio neto de la empresa, principalmente en forma negativa, esto sucede por la forma de registración, en la cual se vincula el interés devengado con el IRACIS y el interés pagado con el IVA cuando la transacción concierne a un periodo a ser devengado, y además el pasivo es afectado con los intereses a pagar. Es importante destacar que el IRACIS es un impuesto con una tasa general del $10 \%$, y esa porción de tasa debe ser provisionada en todas las empresas comerciales para afrontar el descalce financiero que podría suceder si dicho importe fuese considerable. En cambio el IVA al momento del pago inicial se activa, lo cual luego se descarga contra los débitos fiscales, los intereses en general están también gravados al 10\% para el IVA, este impuesto tiene el inconveniente de que corresponde al valor agregado a las transacciones, que dependen de la base imponible para su cálculo, además para el prestamista configura el IVA de los intereses una porción de pasivo que se tiene con la administración tributaria y que debe ser pagado al mes siguiente de su provisión. 
Tabla 5. Libro Diario

\begin{tabular}{|c|c|c|c|c|}
\hline Fecha & Rubro & Concepto & Débitos & Créditos \\
\hline 01/06/2018 & Activo & Bancos Cta. Cte. & 75.000 .000 & \\
\hline 01/06/2018 & $\begin{array}{l}\text { Patrimonio } \\
\text { Neto }\end{array}$ & Capital & & 75.000 .000 \\
\hline 01/06/2018 & $E$ & Saldo Inicial & & \\
\hline 06/06/2018 & Activo & Bancos Cta. Cte. & 250.000 .000 & \\
\hline 06/06/2018 & Pasivo & Préstamos - Partes Relacionadas & & 250.000 .000 \\
\hline $06 / 06 / 2018$ & $E$ & $\begin{array}{l}\text { Por la obtención del préstamo según } \\
\text { comprobantes }\end{array}$ & & \\
\hline 06/06/2018 & Activo & Intereses por Devengar - Partes Relacionadas & 25.000 .000 & \\
\hline 06/06/2018 & Pasivo & Intereses por Pagar - Partes Relacionadas & & 25.000 .000 \\
\hline 06/06/2018 & $E$ & Provisión de los intereses totales & & \\
\hline $30 / 06 / 2018$ & Egresos & Intereses Devengados Partes Relacionadas & 4.166.663 & \\
\hline $30 / 06 / 2018$ & Activo & Intereses por Devengar - Partes Relacionadas & & 4.166 .663 \\
\hline $30 / 06 / 2018$ & $E$ & Devengamiento $1 / 6$ según planilla & & \\
\hline $30 / 06 / 2018$ & Pasivo & Préstamos - Partes Relacionadas & 41.666 .667 & \\
\hline $30 / 06 / 2018$ & Pasivo & Intereses por Pagar - Partes Relacionadas & 4.166.663 & \\
\hline $30 / 06 / 2018$ & Activo & IVA Crédito Fiscal & 416.666 & \\
\hline $30 / 06 / 2018$ & Activo & Bancos Cta. Cte. & & 46.249 .996 \\
\hline $30 / 06 / 2018$ & $E$ & Pago de la cuota $1 / 6$ & & \\
\hline $30 / 07 / 2018$ & Egresos & Intereses Devengados Partes Relacionadas & 4.166 .663 & \\
\hline $30 / 07 / 2018$ & Activo & Intereses por Devengar - Partes Relacionadas & & 4.166 .663 \\
\hline $30 / 07 / 2018$ & $E$ & Devengamiento $2 / 6$ según planilla & & \\
\hline $30 / 07 / 2018$ & Pasivo & Préstamos - Partes Relacionadas & 41.666 .667 & \\
\hline $30 / 07 / 2018$ & Pasivo & Intereses por Pagar - Partes Relacionadas & 4.166.663 & \\
\hline $30 / 07 / 2018$ & Activo & IVA Crédito Fiscal & 416.666 & \\
\hline $30 / 07 / 2018$ & Activo & Bancos Cta. Cte. & & 46.249 .996 \\
\hline $30 / 07 / 2018$ & $E$ & Pago de la cuota $2 / 6$ & & \\
\hline $30 / 08 / 2018$ & Egresos & Intereses Devengados Partes Relacionadas & 4.166 .663 & \\
\hline $30 / 08 / 2018$ & Activo & Intereses por Devengar - Partes Relacionadas & & 4.166 .663 \\
\hline $30 / 08 / 2018$ & $E$ & Devengamiento $3 / 6$ según planilla & & \\
\hline $30 / 08 / 2018$ & Pasivo & Préstamos - Partes Relacionadas & 41.666 .667 & \\
\hline $30 / 08 / 2018$ & Pasivo & Intereses por Pagar - Partes Relacionadas & 4.166.663 & \\
\hline $30 / 08 / 2018$ & Activo & IVA Crédito Fiscal & 416.666 & \\
\hline
\end{tabular}

Fuente: Elaboración Propia (2019). 
Tabla 6. Movimientos en el Balance General

\begin{tabular}{|lrrr|}
\hline \multicolumn{1}{|c}{ Rubros/Cuentas } & Débitos & Créditos & Saldo \\
\hline Activo & $\mathbf{3 5 2 . 4 9 9 . 9 9 9}$ & $\mathbf{3 0 2 . 4 9 9 . 9 9 9}$ & $\mathbf{5 0 . 0 0 0 . 0 0 0}$ \\
\hline Bancos Cta. Cte. & 325.000 .000 & 277.499 .999 & 47.500 .001 \\
IVA Crédito Fiscal & 2.499 .999 & & 2.499 .999 \\
Intereses por Devenqar - Partes Relacionadas & 25.000 .000 & 25.000 .000 & 0 \\
Pasivo & $\mathbf{2 7 5 . 0 0 0 . 0 0 0}$ & $\mathbf{2 7 5 . 0 0 0 . 0 0 0}$ & $\mathbf{0}$ \\
Préstamos - Partes Relacionadas & 250.000 .000 & 250.000 .000 & 0 \\
Intereses por Paqar - Partes Relacionadas & 25.000 .000 & 25.000 .000 & 0 \\
Patrimonio Neto & & $\mathbf{7 5 . 0 0 0 . 0 0 0}$ & $\mathbf{- 7 5 . 0 0 0 . 0 0 0}$ \\
Capital & & 75.000 .000 & -75.000 .000 \\
\hline Total qeneral & $\mathbf{6 2 7 . 4 9 9 . 9 9 9}$ & $\mathbf{6 5 2 . 4 9 9 . 9 9 9}$ & $\mathbf{- 2 5 . 0 0 0 . 0 0 0}$ \\
\hline
\end{tabular}

Fuente: Elaboración Propia (2019).

Tabla 7. Movimientos en el Estado de Resultados

\begin{tabular}{|ccrrr|}
\hline \multicolumn{1}{|c}{ Rubros/Cuentas } & Débitos & Créditos & Saldo \\
Earesos & $\mathbf{2 5 . 0 0 0 . 0 0 0}$ & & $\mathbf{- 2 5 . 0 0 0 . 0 0 0}$ \\
Intereses Devenqados Partes Relacionadas & 25.000 .000 & & -25.000 .000 \\
\hline \multicolumn{2}{|c|}{ Total qeneral } & $\mathbf{2 5 . 0 0 0 . 0 0 0}$ & & $\mathbf{- 2 5 . 0 0 0 . 0 0 0}$ \\
\hline
\end{tabular}

Fuente: Elaboración Propia (2019).

\section{CONCLUSIONES}

Los costos por intereses establecidos por la NIC N²3 “Costos por Préstamos" son desarrollados por dicha norma en cuanto a sus características de registración y medición, entra las cuales se pueden mencionar como las más significativas: a) los costos por intereses serán capitalizados si su uso corresponde al periodo de puesta en marcha del activo y durante el avance de la obra, b) Cuando el periodo de capitalización hubiere terminado se cancelará la activación de los costos por intereses, y serán registrados en cuentas de gastos en el ejercicio fiscal al que correspondiere el devengamiento. El periodo de capitalización puede ser considerable de acuerdo al tipo de empresa comercial, lo cual hace que una extensión del tiempo afecte al pago de tributos, y por ende disminuya proporcionalmente su patrimonio.

En este artículo, también se hizo mención a que la legislación tributaria paraguaya mediante el Decreto reglamentario del IVA 1030/2013 y sus modificaciones grava los intereses con una tasa del $10 \%$ para todas las operaciones de préstamos en general, que en el caso de instituciones financieras es de gran significación, por ser estos intereses sus principales fuentes de ingresos. Se destaca también la reglamentación establecida en el Decreto 6359/2005 sobre el IRACIS, el cual menciona la deducibilidad de los intereses pagados cuando fueren los mismos, partes de la operativa normal del negocio. Además, se aclara que su registración deberá ser como egresos operativos en el estado de resultados. La no deducibilidad de los intereses sucederá cuando el interés pagado no tenga relación con el giro del negocio o no se tenga la documentación respaldatoria correspondiente, esta no deducibilidad crea otras obligaciones tributarias que afectan también al patrimonio de la empresa comercial.

En cuanto a los ejercicios propuestos, se pudo establecer que los intereses por préstamos son afectados significativamente por los Decretos 6359/2005, Decreto 1030/2013 y la NIC 23, pues los mismos generan una disminución proporcional en el patrimonio de las empresas comerciales. Como investigaciones posteriores se sugiere un análisis longitudinal de las provisiones sobre intereses y sus repercusiones en el pasivo financiero de las empresas comerciales. 


\section{REFERENCIAS BIBLIOGRÁFICAS}

Allen, F., Myers, S., \& Brealey, R. (2010). Principios de Finanzas Corporativas (9o ed.). México D.F.,México: McGraw-Hill/Interamericana Editores, S.A. DE C.V.

Congreso de la Nación Paraguaya. (1969). Ley N 154/1969 “De Quiebras”. Asunción, Paraguay: Autor.

Congreso de la Nación Paraguaya. (1983). Ley N 1034/1983 “Del Comerciante”. Asunción, Paraguay: Autor.

Congreso de la Nación Paraguaya. (1990). Ley N 60/1990 “De Inversiones”. Asunción, Paraguay: Autor.

Congreso de la Nación Paraguaya. (1994). Ley N 438/1994 “De Cooperativas". Asunción, Paraguay: Autor.

Congreso de la Nación Paraguaya. (1996). Ley N 805/1996 “Del Cheque Bancario de Pago Diferido". Asunción, Paraguay: Autor.

Congreso de la Nación Paraguaya. (1996). Ley N 861/1996 “De Bancos, Financieras y Otras Entidades de Crédito". Asunción, Paraguay: Autor.

Congreso de la Nación Paraguaya. (1996). Ley N 921/1996 “De Negocios Fiduciarios". Asunción, Paraguay: Autor.

Horngren , C., Datar, S., \& Rajan, M. (2012). Contabilidad de Costos. Un Enfoque Gerencial (14은 ed.). México D.F., México: Pearson Educación de México S.A. de C.V.

IASB. (2015). NIC 23 Costos por Préstamos. Londres, Reino Unido: Autor.

Ortíz, A., \& Rivero, G. (2006). Estructuración de Costos: Concepto y Metodología. Washington, EE.UU.: Pactworld.

Poder Ejecutivo. (2005). Decreto № 6359/2005 “Por el cual se reglamenta el Impuesto a la Renta de Actividades Comerciales, Industriales o de Servicios previsto en el Capítulo I del Libro I de la Ley N²125/1991". Asunción, Paraguay: Autor.

Poder Ejecutivo. (2013). Decreto № 1030/2013 “Por el cual se reglamenta el Impuesto al Valor Agregado (IVA) establecido en la Ley N¹25/1991 y sus Modificaciones”. Asunción, Paraguay: Autor.

Poder Ejecutivo. (2014). Decreto № 1440/2014 “Por el cual se modifican los artículos 24, 29 y 30 del Anexo al Decreto N¹030/2013". Asunción, Paraguay: Autor.

Ramírez, D. (2008). Contabilidad Administrativa. México D.F.: McGraw-Hill /Interamericana Editores, S.A. de C.V.

Rodríguez, C. (2013). Diccionario de Economía: Etimológico, Conceptual y Procedimental. Edición especial para Estudiantes. Mendoza, Argentina: Universidad Católica Argentina.

Saavedra, C. (2010). El Arrendamiento Financiero (Leasing) en la Gestión Financiera de las Micro y Pequeñas Empresa (MYPES) en el Distrito de la Victoria (Tesis). Lima, Perú: Universidad de San Martín de Porres.

Sabino, C. (1991). Diccionario de Economía y Finanzas. Caracas, Venezuela: Panapo. 